\title{
Pediatric early warning score as a prognostic indicator in critically ill children - a prospective study
}

\author{
Ramteke S. ${ }^{1}$, Tikkas R. ${ }^{2}$, Jain $\mathbf{A .}^{3}$ \\ ${ }^{1}$ Dr. Sharmila Ramteke, Assistant Professor, ${ }^{2}$ Dr. Rajesh Tikkas, Associate Professor, ${ }^{3}$ Dr. Ankit Jain, Senior Resident, \\ all authors are affiliated with Department of Pediatrics, Gandhi Medical College Bhopal, MP, India.
}

Corresponding Author: Dr. Rajesh Tikkas, Associate Professor, Department of Pediatrics, Gandhi Medical College, Bhopal (MP) India. Email id-raj_tikkas@rediffmail.com

\begin{abstract}
Introduction: The early identification of patients at risk of clinical deterioration and matching the severity of illness to the appropriate level of care are integral components of high-quality medical care. Aconcept for identifying early signs of deterioration is the use of an early warning score tool that combines clinical parameters into a single score. The rationale for using early warning scoring systems is that signs of deterioration have been shown to be present and detectable in many patients several hours before undergoing a serious life-threatening event. Methods: A prospective observational study was conducted in the Department of Pediatrics G.M.C. Bhopal, M.P. A total of 257 patients (1 month - 14 years) withan acute problem, who were admitted in PICU,were included. At 0-hourof admission Pediatric Early Warning Score (PEWS) was calculated in different domains - behavioural, respiratory and the cardiovascular. Then sensitivity and specificity were calculated fora specific score. Results: Specificity was $92.0 \%$ at PEWS Score of 3 and declines to $54.55 \%$ at PEWS Score of 7. Sensitivity was 31.28\% at PEWS score of 3 and rises to 99.05 at PEWS Score of 7. Conclusion: PEWS is highly sensitive and specific in predicting the mortality, differentially against the various PEWS scores.
\end{abstract}

Keywords: Pediatric Early Warning Score, Screening tool, patients at risk

\section{Introduction}

The early identification of patients at risk of clinical deterioration and matching the severity of illness to the appropriate level of care are integral components of high-quality medical care, as is appropriate resource allocation in the hospital setting [1]. Patients who are admitted to hospital believe that they are entering a place of safety, and they, and their families have a right to believe that they will receive the best possible care there.

They feel confident that should their condition deteriorate, they are in the best place for prompt and effective treatment but, the late recognition and treatment of these patients in the hospitalhas been evidenced. The greater complexity of patients admitted to the wards, the difficulties of some professionals in recognizing the severity, and the shortage of trained urgency and emergency staff are examples of conditions that may lead to delays in the recognition of clinical

Manuscript received: $10^{\text {th }}$ January 2018

Reviewed: $20^{\text {th }}$ January 2018

Author Corrected: $28^{\text {th }}$ January 2018

Accepted for Publication: $5^{\text {th }}$ February 2018 deterioration in hospitalized children [2]. Studies in the past has demonstrated that the signs and symptoms of the impending cardio pulmonary arrest often goes undetected due to lack of health care experience or overburdening of the health care staff due to high patient acuity. Older studies highlighted the need for a screening tool that could quickly and easily assess risk of cardio pulmonary arrest and provide guidelines for clinical management based on this assessment. Early recognition of the signs and symptoms of the clinical deterioration in the children is a key factor for the survival and good prognosis. The challenge in intervening to prevent cardio pulmonary arrest lies in the ability of health care providers to identify the early signs of deterioration and to intervene. Two such concepts for early identification and intervention for deteriorating patients are the implementation of a medical emergency team (MET) and the use of an early warning score. An additional concept for identifying early signs of deterioration is the use of an early warning score tool that combines clinical parameters into a single score. 
The rationale for using early warning scoring systems is that signs of deterioration have been shown to be present and detectable in many patients several hours before undergoing a serious life-threatening event [3]. The purpose of the early warning system tools is to alert the staff about the decline in the clinical status of patients using predetermined criteria so that the needed interventions and resources are made available for the children before their health status deteriorates further.

The early warning score tool for children, the PEWS, consists of three items related to the patient's behavior, cardiovascular status, and respiratory status.Scores for the PEWS scale can range from 0 to 9 , with a higher number representing a higher risk of clinical deterioration [4].

Pediatric Early Warning Score isan objective assessment tool to identify patients with serious physiological distur bances at riskof deterioration which may give us a numeric trend in the patient condition. We did a study to see the sensitivity and specificity of PEWS in predicting mortality and morbidity.

\section{Material and Methods}

Study Type -A prospective observational study. Place of Study - Department of Pediatrics G.M.C. Bhopal (M.P.), INDIA.

Sample Collection - A total of 257 patients of the age group between more than 1 month and 14 years of age were studied. The study duration was from March 2015 to February 2016.

Sampling Methods - The number of cases to be studied was calculated using the formula ( $4 \mathrm{pq} / \mathrm{L}^{2} \mathrm{P}=\mathrm{prevalence,} \mathrm{Q}=1-\mathrm{p}$, $\mathrm{L}=$ level of error), considering the incidence to be $\sim 80 \%$ in the hospital and $5 \%$ as level of error.

Inclusion Criteria- All patients who presented to the PICU with an acute problem and without any underlying chronic illness were included in the study during the study period.

Exclusion Criteria- The patients who were suffering from -

1. Any chronic illness

2. Any surgical or any pre-existing disease apart from the acute illness.

Before recording the data of the patients a written informed consent was obtained from the parents/ guardians of the case in the predesigned format. All basic details of the cases were recorded on a pretested proforma which included age, sex, residence, father's name. Anthropometric measurement was taken along with the vitals of the cases. A thorough general examination and the systemic examination of the cases was done and recorded.

As per the predefined criteria mentioned in the PEWS charts, the cases were assigned numbers in different domains of the PEWS i.e. behavioural, respiratory and the cardiovascular domains at the time of admission

Pediatric Early Warning Score[5].

\begin{tabular}{|c|c|c|c|c|}
\hline & $\mathbf{0}$ & $\mathbf{1}$ & $\mathbf{2}$ & $\mathbf{3}$ \\
\hline Behaviour & $\begin{array}{c}\text { Playing/ } \\
\text { appropriate }\end{array}$ & Sleeping & Irritable & $\begin{array}{c}\text { Lethargic/confused } \text { or reduced } \\
\text { response to pain }\end{array}$ \\
\hline Cardiovascula & $\begin{array}{c}\text { Pink or capillary } \\
\text { refill 1-2 seconds }\end{array}$ & $\begin{array}{c}\text { Pale or capillary refill } \\
3 \text { seconds }\end{array}$ & $\begin{array}{c}\text { Gray or capillary } \\
\text { refill } 4 \text { seconds } \text { or } \\
\text { tachycardia of } 20 \\
\text { above normal rate }\end{array}$ & $\begin{array}{c}\text { Gray and mottled or capillary } \\
\text { refill } 5 \text { seconds or above } \text { or } \\
\text { tachycardia of } 30 \text { above normal } \\
\text { rate } \text { or bradycardia }\end{array}$ \\
\hline Respiratory & Within normal & $>10$ above normal \\
parameters, no & parameters using \\
retractions & $\begin{array}{c}>20 \text { above normal } \\
\text { parameters and } \\
\text { retractions } \text { or } 40+ \\
\% \mathrm{FiO}_{2} \text { or } 6+\mathrm{L} / \mathrm{min}\end{array}$ & $\begin{array}{c}\text { Five below-normal parameters } \\
\text { with retractions and grunting } \text { or } \\
50 \% \text { FiO }\end{array}$ \\
\hline
\end{tabular}

Statistical Analysis- PEWS scoring of the cases was done at the time of admission. After assigning PEWS in various domains cumulative PEWS score was calculated by adding the numbers obtained in various domains of the PEWS. The data obtained from the cases was recorded in the pre-designedformats. The observations were summarized into the tables 
and the tables were analysed. Sensitivity and specificity was calculated. In each group outcomes of the cases in the forms of discharge and deaths was calculated. The data was analyzed using SPSS 20. Appropriate univariate statistical analysis was carried out using the Student's $t$ test for the continuous variable and two-tailed Fisher exact test or chi-square $\left(\mathrm{c}^{2}\right)$ test for categorical variables.

To measure the linear dependence between two random variables Pearson's correlation co-efficient was used. All means are expressed as mean \pm standard deviation and proportion in percentages are expressed as mean \pm standard deviation. The critical levels of significance of the results were considered at 0.05 levels i.e. $\mathrm{P}<0.05$ was considered significant

The permission of the Ethical Committee was taken before conducting the study.

\section{Results}

A prospective observational study was conducted in the Pediatric Intensive Care Unit (PICU) of the Department of Pediatrics, G.M.C. Bhopal from March 2015 to February 2016, in which 257 cases were studied.

$97.7 \%$ of the cases belonged to the age group less than 12 years of age (Figure 1). In our study we found a male preponderance amongst the admitted cases, with female ratio of 1.6:1. The mortality incidence per female cases admitted was almost double in the female patients $(23.2 \%)$ as compared to the male group $(13.9 \%)$.

Maximum number of cases at the time of admission had PEWS score of 3 or 4 . Those patients who had PEWS score 0,1 and 2 at admission, all were discharged. (Figure 2). In rest of the patient there was almost a linear trend between, PEWS and the number of deaths of the corresponding groups.

There was $100 \%$ mortality of the cases whose PEWS was 8 at admission (Figure 2). In our study, results of logistic regression analysis showed a highly significant $\mathrm{P}$ value $(\mathrm{P}<0.0001)$ and the odds ratio was 3.34 (Table 1$)$. Therefore, statistically significant relation exists between the variables (Figure 3). Specificity was $92.0 \%$ at PEWS Score of 3 and declines to $54.55 \%$ at PEWS Score of 7. Sensitivity was $31.28 \%$ at PEWS score of 3 and rises to 99.05 at PEWS Score of 7 (Figure 4).

Table-1: Logistic Regression of PEWS at '0' Hours of Admission and outcome

\begin{tabular}{|c|c|c|}
\hline Variable & P VALUE & ODDS RATIO \\
\hline PEWS Score & $<0.00001$ & 3.34 \\
\hline Intercept & $<0.00001$ & \\
\hline
\end{tabular}

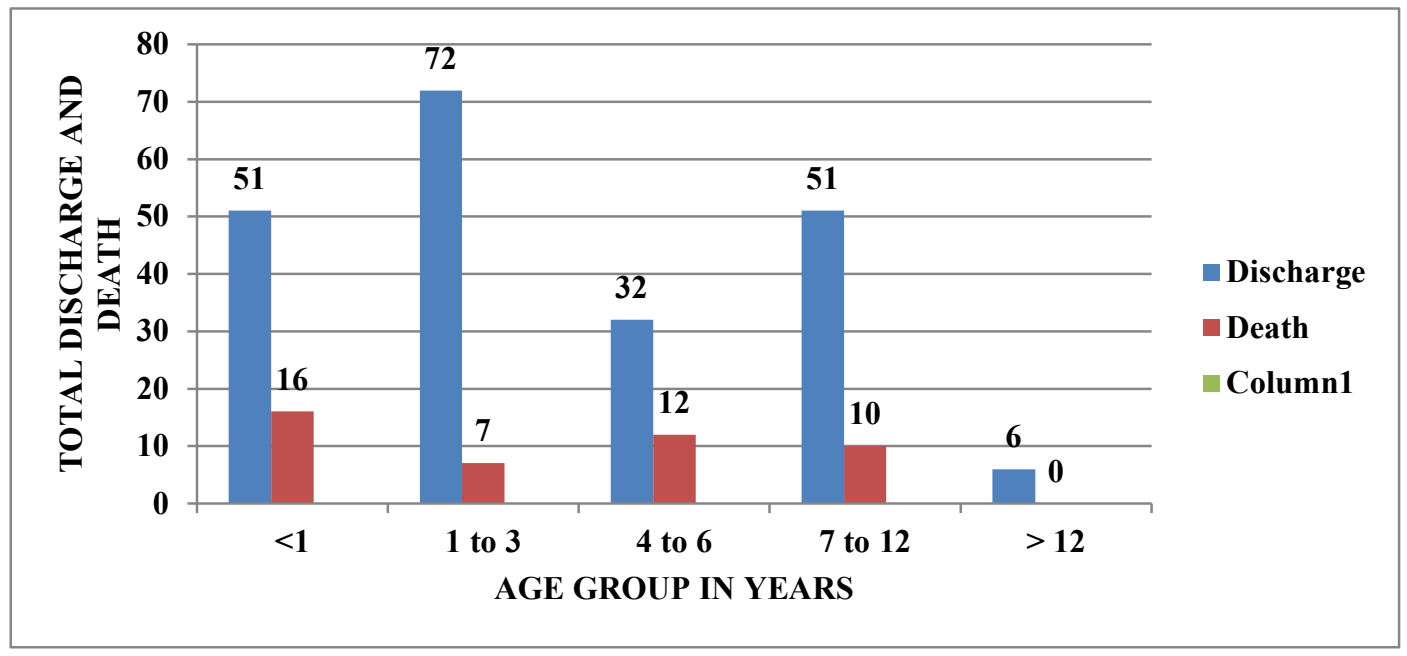

Figure-1: Age wise distribution of the cases and their distribution 
Editorial

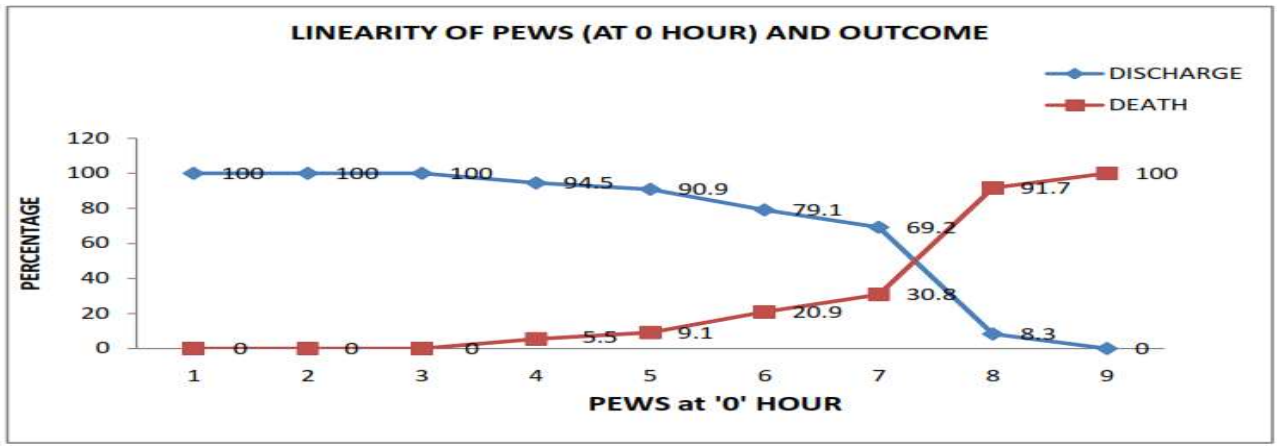

Figure-2: Distribution of the Cases According To the PEWS at Admissionandtheir Outcome

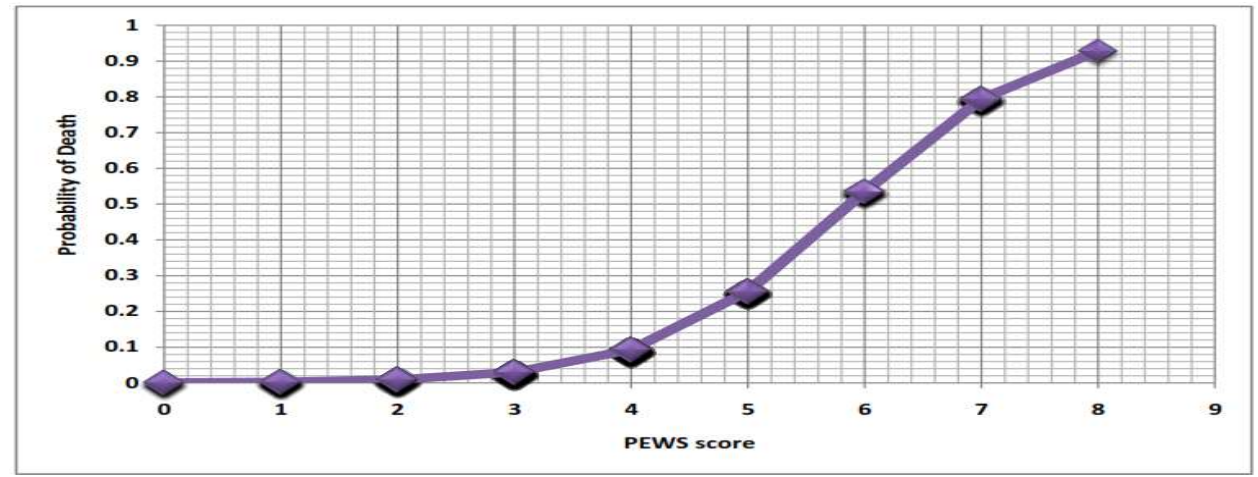

Figure 3. Logistic regression of PEWS at admission and outcome

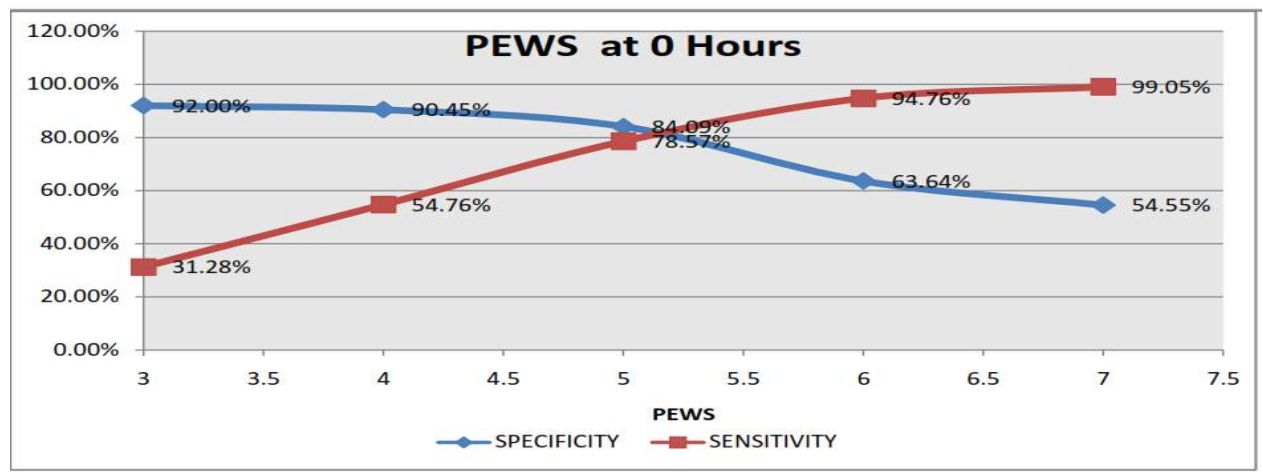

Figure-4: Sensitivity and Specificity of PEWS at Admission

\section{Discussion}

A prospective observational study was conducted in the Pediatric Intensive Care Unit (PICU) of the Department of Pediatric, G.M.C. Bhopal from March 2015 to February 2016, in which 257 cases were studied and at the completion of our study we tabulated our findings and analysed data. In our study there was an approximately equal distribution of cases in each age group, andthere was no age specific significant deviation in the mortality patterns towards any age group. Mortality percentage was approximately same in each age group (23\%). We did the PEWS scoring of the patients at the time of admission and found that maximum number of patients were admitted at the PEWS score of 3 and 4, collectively constituting $42.8 \%$ of the total cases. We found that percentage of discharge was maximum $(100 \%)$ in the cases who had a low PEWS at the time of admission (PEWS 0,1 and 2) and the increase in the number of deaths had almost a linear trend with the increase in PEWS $(100 \%$ mortality at a PEWS score of 8 , scoring done at admission). $\mathrm{R}$ Paterson et al[6] found that early warning score, at the time of admission was correlated both with in-hospital mortality $(\mathrm{p}<0.001)$ and length of stay $(\mathrm{P}=0.01)$. They further found that with the early MEWS (modified early 
warning score), a score of 5 or greater than 5 was associated with an increased risk of in-hospital death. Dan Olson et al[7] in their study, found, that a ITAT score of 4 or higher is associated with increased odds of death.

The results of the study done by Maria Niña Banque et al[8], showed a significant co-relation between PEWS and clinical deterioration. PEWS of $>4$ was well correlated with PICU set-up admission and mortality. In our studya logistic regression of PEWS at admission was calculated against the probability of the death of the cases. The graph showed a positive co-relation between the death and the PEWS at the time of admission. The relationship between the PEWS and the death showed almost a linear relationship between PEWS and the probability of death.

At lower PEWS the probability of death was less or there was almost no death at the PEWS score of 0,1 and 2 and from the PEWS score of 3 the probability of death increases almost linearly with the increase in PEWS.

In our studysensitivity and specificity of PEWS, at admission was calculated. Sensitivity was $92.0 \%$ at PEWS Score of 3 and declines to $54.55 \%$ at PEWS Score of 7. Specificity was $31.28 \%$ at PEWS score of 3 and rises to 99.05 at PEWS Score of 7 .

Peter J Lillitos [9] in his study, found that PEWS 3 or greater was highly specific but poorly sensitive. PEWS 3 is $75 \%$ sensitive and $91 \%$ specific in predicting respiratory illness. Christopher S Parshuram[10] in his found that at a score of 8 the sensitivity and specificity of the PEWS was $82 \%$ and $93 \%$ respectively.

Marry -Ann J Robson et al [2013][11] in their study, found that the PEWscore System demons trated a sensitivity of $86.6 \%$ and specificity $72.9 \%$ at a score of five. Peter J Lillitos et al [9], concluded that PEWS of $\geq$ 3 was specific (93\%) but poorly sensitive (32\%). In our study we found a median PEWS 3 among the survived and 7 amongst the patients who died. So, a high PEWS should be taken seriously but a low score is poor at ruling out the requirement for admission or serious underlying illness

\section{Conclusions}

In our study we found that PEWS is highly sensitive and specific in predicting the mortality, differentially against the various PEWS scores. There is almost a linear trend between the probability of death and the
PEWS. PEWS can be used to predict the mortality. With the help of PEWS the alteration in the physiological parameters can be converted into scores and appropriate action can be taken according to the alteration in the scores.

Author's contribution: SR: Acquisition and interpretation of data, data analysis, drafting the article, and literature review, will act as a guarantor; RT: Concept, manuscript editing, revising the article critically for important intellectual content. AJ: Data analysis, manuscript review, manuscript editing.

What this study adds - With the help of PEWS system we can prioritize critically ill patients coming in emergency department and provide appropriate management.

\section{Abbreviations}

MET- Medical Emergency Team, PEWS - Pediatric Early Warning Score, MEWS - Modified early warning score, ITAT- Inpatient Triage, Assessment and Treatment, PICU- Pediatric Intensive Care Unit.

Funding: Nil, Conflict of interest: None initiated, Perission from IRB: Yes

\section{References}

1. Parshuram CS, Hutchinson J, Middaugh K.. Development and initial validation of the Bedside Paediatric Early Warning System score.Crit Care. 2009; 13: R135

2. Juliana de Oliveira Freitas Miranda, Climene Laura de Camargo, Carlito Lopes Nascimento Sobrinho, Daniel Sales Portela,. Alan Monaghan. Accuracy of a pediatric early warning score in the recognition of clinical deterioration1. Rev. Latino-Am. Enfermagem vol.25 Ribeirão Preto 2017 Epub July 10, 2017http: //dx. doi.org/10.1590/1518-8345.1733.2912

3. Anne L. Solevåg, Elisabeth H. Eggen, Judith Schröder, Britt Nakstad Use of a Modified Pediatric Early Warning Score in a Department of Pediatric and Adolescent Medicine PLOS. Published: August 26, 2013 https: //doi. org/10.1371/ journal. pone. 007 2534.

4. Tucker KM, Brewer TL, Baker RB, Demeritt B, Vossmeyer MT. Prospective evaluation of a pediatric inpatient early warning scoring system. J Spec Pediatr Nurs. 2009 Apr; 14 (2):79-85. doi: 10.1111/j.17446155.2008.00178.x. 
Editorial

5. Delia L. Gold, Leslie K. Mihalov, Daniel M. Cohen. Evaluating the Pediatric Early Warning Score (PEWS) System for Admitted Patients in the Pediatric Emergency Department. AcadEmerg Med. 2014 Nov; 21 (11): 1249-1256.

6. Paterson R, MacLeod DC, Thetford D, Beattie A, Graham C, Lam S, Bell D. Prediction of in-hospital mortality and length of stay using an early warning scoring system: clinical audit.Clin Med (Lond).2006 May-Jun;6(3):281-4.

7. Dan Olson, Nicole L. Davis, Robert Milazi, Norman Lufesi, William C. Miller, Geoffrey A. Preidis, Mina C. Hosseinipour, and Eric D. Mc Collum (2014). Development of a severity of illness scoring system (ITAT) for resource-constrained hospitals in developing countries. Tropical Medicine and International Health volume 18 no 7 pp 871-878 Pg 5July 2013.

8. Maria Niña Banque, Doris Louise Obra (2011). Correlation of the Pediatric Early Warning Score
(PEWS) and Clinical Deterioration Among Children Admitted in a Private Tertiary Hospital. Chest Journal October 2011, Vol 140, No. 4

9. Peter J Lillitos, Graeme Hadley, Ian Maconochie (2016) Can pediatric early warning scores (PEWS) be used to guide the need for hospital admission and predict significant illness in children presenting to the emergency department. Emerg Med J. doi:10.1136/ emermed-2014-204355.

10. Parshuram CS, Hutchison J, Middaugh K. Development and initial validation of the Bedside Paediatric Early Warning System score.Crit Care. 2009; 13(4): R135. doi: 10.1186/cc7998. Epub 2009 Aug 12.

11. Robson MA, Cooper CL, Medicus LA, Quintero MJ, Zuniga SA. Comparison of three acute care pediatric early warning scoring tools.J PediatrNurs. 2013 Nov-Dec;28(6):e33-41. doi: 10.1016/j.pedn. 2012. 12.002. Epub 2012 Dec 28.

\section{How to cite this article?}

Ramteke S, Tikkas R, Jain A. Pediatric early warning score as a prognostic indicator in critically ill children - a prospective study. Int J Pediatr Res. 2018;5(2):66-71. doi:10.17511/ijpr.2018.i02.05. 